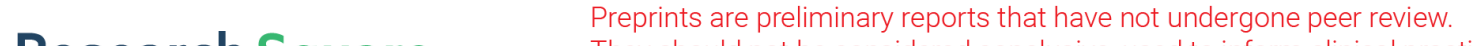 They should not be considered conclusive, used to inform clinical practice, or referenced by the media as validated information. \\ Robust effects of springtime Arctic ozone depletion on surface climate
}

Marina Friedel ( $\triangle$ marina.friedel@env.ethz.ch )

ETH Zurich https://orcid.org/0000-0001-7739-4691

\section{Gabriel Chiodo}

ETH Zurich https://orcid.org/0000-0002-8079-6314

\section{Andrea Stenke}

ETH Zürich https://orcid.org/0000-0002-5916-4013

\section{Daniela Domeisen}

ETH Zurich https://orcid.org/0000-0002-1463-929X

\section{Stephan Fueglistaler}

Princeton University https://orcid.org/0000-0002-0419-440X

Julien Anet

ZHAW

\section{Thomas Peter}

Institute for Atmospheric and Climate Science

\section{Article}

Keywords: ozone loss, Arctic, springtime, surface climate

Posted Date: May 25th, 2021

DOI: https://doi.org/10.21203/rs.3.rs-496081/v1

License: (9) This work is licensed under a Creative Commons Attribution 4.0 International License.

Read Full License

Version of Record: A version of this preprint was published at Nature Geoscience on July 7th, 2022. See the published version at https://doi.org/10.1038/s41561-022-00974-7. 


\title{
Robust effects of springtime Arctic ozone depletion on surface climate
}

\author{
Marina Friedel ${ }^{1, *}$, Gabriel Chiodo ${ }^{1,2}$, Andrea Stenke ${ }^{1}$, Daniela I.V. Domeisen ${ }^{1}$, Stephan \\ Fueglistaler $^{3,4}$, Julien Anet ${ }^{5}$, and Thomas Peter ${ }^{1}$
}

\author{
${ }^{1}$ ETH Zürich, Institute for Atmospheric and Climate Science, Zürich, Switzerland \\ ${ }^{2}$ Applied Physics and Applied Math, Columbia University, NY, USA \\ ${ }^{3}$ Department of Geosciences, Princeton University, Princeton, NJ, USA \\ ${ }^{4}$ Program in Atmospheric and Oceanic Sciences, Princeton University, Princeton, NJ, USA \\ ${ }^{5}$ ZHAW, School of Engineering, Winterthur, Switzerland \\ *marina.friedel@env.ethz.ch
}

\begin{abstract}
Massive spring ozone loss due to anthropogenic emissions of ozone depleting substances is not limited to the austral hemisphere, but can also occur in the Arctic. Previous studies have suggested a link between springtime Arctic ozone depletion and Northern Hemispheric surface climate, which might add surface predictability. However, so far it has not been possible to isolate the role of stratospheric ozone from dynamical downward impacts. For the first time, we quantify the impact of springtime Arctic ozone depletion on surface climate using observations and targeted chemistry-climate model experiments to isolate the effects of ozone feedbacks. We find that springtime stratospheric ozone depletion is followed by surface anomalies in precipitation and temperature resembling a positive Arctic Oscillation. Most notably, we show that these anomalies, affecting large portions of the Northern Hemisphere, cannot be explained by dynamical variability alone, but are to a significant degree driven by stratospheric ozone. The surface signal is linked to reduced shortwave absorption by stratospheric ozone, forcing persistent negative temperature anomalies in the lower stratosphere and a delayed breakup of the polar vortex - analogous to ozone-surface coupling in the Southern Hemisphere.These results suggest that Arctic stratospheric ozone actively forces springtime Northern Hemispheric surface climate and thus provides a source of predictability on seasonal scales.
\end{abstract}

In the Southern Hemisphere (SH), polar stratospheric ozone has declined drastically since the 1980s due to anthropogenic emissions of gases such as chlorofluorocarbons (CFCs) and bromine-containing halons, resulting in the yearly formation of an ozone hole over the Antarctic in austral spring ${ }^{1}$. This decrease in ozone is not only critical for human health and ecosystems ${ }^{2,3}$, but has been linked to large-scale climatic changes in the $\mathrm{SH}^{4-7}$. While long-term changes in $\mathrm{SH}$ surface climate have been clearly attributed to radiative and dynamical impacts of Antarctic ozone depletion ${ }^{8}$, recent studies also show a clear connection between the state of the Antarctic ozone layer in spring and subsequent surface climate on seasonal timescales ${ }^{7,9,10}$.

Owing to stronger planetary wave fluxes in the Northern Hemisphere $(\mathrm{NH})$, which result in increased transport of ozone-rich air into the polar regions and less favorable conditions for ozone depletion compared to the $\mathrm{SH}$, the observed ozone trend over the Arctic is much smaller than over the Antarctic. However, drastic springtime ozone loss with magnitudes typical for Antarctic ozone depletion has been observed in the Arctic stratosphere, most recently in spring $2020^{11,12}$. Recent observations and model simulations suggest that such low springtime Arctic ozone concentrations are followed by surface anomalies resembling a positive phase of the Arctic Oscillation (AO) ${ }^{13,14}$, similar to observations in the $\mathrm{SH}$. Some analyses argue that this ozone-surface climate connection could be useful for statistical predictions of $\mathrm{NH}$ seasonal climate ${ }^{15,16}$.

However, it remains difficult to disentangle the potential downward influence of ozone extremes from extreme dynamical events in the stratosphere, for which a surface impact is well established ${ }^{17-19}$. Surface patterns coincident with ozone depletion might be caused entirely by dynamical variability in the lower stratosphere, with ozone simply acting as a passive tracer of such dynamical variability ${ }^{20,21}$. Conversely, some studies based on models and observations conclude that ozone extremes actively influence surface climate ${ }^{13,14}$. These conflicting results arise from both a lack of simulations which explicitly isolate the ozone feedbacks, and the specific analysis methods used in past studies. Until now, there is neither robust evidence for a causal link between springtime stratospheric ozone and NH surface climate, nor have the feedback processes driven by ozone been quantitatively assessed. Moreover, past studies focused on monthly averaged climate variables and chose fixed reference months (March/April) to define springtime ozone extremes, ignoring inter-annual variations in the timing of those events. In addition, they assessed the ozone-surface climate link by contrasting years with high and low springtime Arctic ozone concentrations ${ }^{13-15}$, which does not allow them to isolate the surface signal forced by ozone depletion due to the mutual dependence of ozone and stratospheric dynamics. 
Here, we shed new light on the surface impacts of Arctic ozone depletion by (1) isolating ozone feedbacks from dynamical contributions in model simulations and by (2) improving the detection of ozone depletion events and their surface signature through consideration of their relative timing. A better understanding of the ozone contribution is expected to improve surface forecasts ${ }^{15,16,22}$, which further motivates investigation of the effects of Arctic ozone depletion on surface climate.

\section{Ozone-surface climate connection in observations}

We start by revisiting springtime ozone depletion and associated surface patterns from 1980 to 2020 in the MERRA2 reanalysis dataset $^{23}$. We define springtime ozone minima based on partial stratospheric ozone column $(30-70 \mathrm{hPa})$ over the polar cap $\left(60-90^{\circ} \mathrm{N}\right)$. For each year, the minima in daily ozone values within March and April are identified and ranked, and the day exhibiting the lowest ozone value is termed as "central ozone minimum date". In the following, we use the terms "ozone minima" and "ozone depletion" interchangeably (see supplementary material and Fig. S9). For further analysis, the 10 years $25 \%$ of the 41 year-long period - with the lowest springtime ozone values are considered. This detection method allows for a better alignment of stratospheric ozone depletion and associated surface effects compared to previous studies ${ }^{13,14}$.

In the 30 days following the central ozone minimum date we predominantly find negative sea level pressure (SLP) anomalies in the polar region and positive SLP anomalies in midlatitudes, especially over northwestern Europe (Fig. $1 \mathrm{a}-\mathrm{c}$ ). This pattern resembles the positive phase of the $\mathrm{AO}$, consistent with previous results in the context of ozone extremes ${ }^{13}$. The positive $\mathrm{AO}$ is associated with regional temperature anomalies; we find warming over Siberia and large parts of Eurasia (up to $2 \mathrm{~K}$ ) as well as over western Europe (up to $1 \mathrm{~K}$ ), which is adjacent to cooling over southeastern Europe. As expected for a positive AO, we find that Arctic ozone depletion is followed by reduced precipitation over large parts of Europe and central Asia, and increased precipitation over the Arctic.

Even though we find a strong connection between stratospheric ozone depletion and a positive AO at the surface, the spread in the mean $\mathrm{AO}$ index averaged over the month after the central date between individual events is large, and for 2 out of the 10 events the AO is negative (Fig. 2). This spread is similar to the variable tropospheric response after Sudden Stratospheric Warmings $\left(\mathrm{SSWs}^{24}\right)^{25-27}$. Yet, we see a clear shift towards a predominantly positive phase of the AO in the aftermath of stratospheric ozone depletion. Our results not only confirm the robust statistical connection between springtime stratospheric ozone values and surface climate reported previously, but the new detection method used here reveals an even larger surface signal following stratospheric ozone depletion than reported by past studies ${ }^{13,14}$ (see Fig. S8).

\section{Isolating the influence of ozone on surface climate}

In order to establish the causality of the ozone-surface coupling, we perform targeted model experiments designed to isolate ozone feedbacks, meaning the ozone impact on stratospheric dynamics and surface climate. We use two chemistry-climatemodels, WACCM $4^{28}$ and SOCOL-MPIOM ${ }^{29}$. These models have different dynamical cores and chemistry modules (see methods). With both models, we perform two simulations: one with fully interactive ozone chemistry (INT_O3) and one with prescribed climatological ozone (CLIM_O3). Both integrations employ present-day boundary conditions. Unlike other studies using a similar set-up ${ }^{30-32}$, experiments with prescribed ozone climatologies (CLIM_O3) still employ the chemistry scheme. However, in these experiments, the three-dimensional ozone field is radiatively inactive. Thus, ozone purely acts as a passive tracer in CLIM_O3 and ozone feedbacks on the atmospheric circulation are disabled. A similar set-up has already been used in the context of SH ozone depletion ${ }^{33}$. Here, this approach allows us to apply the same definition for detecting the $25 \%$ most extreme ozone minima as for reanalysis (50 events out of 200 simulated years) in both CLIM_O3 and INT_O3 experiments (see methods). While simulations with CLIM_O3 represent pure dynamical effects, experiments with interactive chemistry (INT_O3) explicitly allow for feedbacks between ozone and stratospheric dynamics.

In runs with specified ozone chemistry (CLIM_O3) in WACCM, springtime ozone minima are followed by significant negative SLP anomalies over the polar cap, positive temperature anomalies over large parts of Eurasia and increased precipitation close to the pole (Fig. $1 \mathrm{~g}-\mathrm{i}$ ). Since ozone anomalies do not exert any radiative-dynamical feedback in the CLIM_O3 setting, these springtime surface anomalies are solely due to dynamical variability and are linked to an exceptionally strong polar vortex and a cold stratosphere. Surface anomalies in CLIM_O3 following Arctic ozone depletion are thus comparable to observations in their sign and pattern for large parts of the $\mathrm{NH}$, but are substantially weaker (cp. to Fig. 1 a-c). This suggests that surface patterns found in the observations cannot be explained by dynamical variability alone.

Runs with interactive ozone (INT_O3), which additionally include ozone feedbacks, show significantly enhanced surface anomalies compared to CLIM_O3 in the 30 days after springtime Arctic ozone depletion. More specifically, negative SLP anomalies over the pole are up to $4 \mathrm{hPa}$ larger (Fig. $1 \mathrm{~d}$ ), temperature anomalies in Eurasia are enhanced by more than $1 \mathrm{~K}$ (Fig. $1 \mathrm{e}$ ) and precipitation anomalies over the Arctic are increased (Fig. $1 \mathrm{f}$ ). In addition, the INT_O3 experiments also capture the observed high SLP and temperature anomalies as well as dry anomalies over northwestern Europe: this pattern is absent in CLIM_O3 (Fig. 1 d-i, red boxes). Most notably, the distribution of the AO index and its mean $(0.50)$ in the month after the central date in INT_O3 is comparable to the AO index in reanalysis with a mean of 0.52 , while the mean is close to zero in CLIM_O3 (Fig. 2). 
Since differences in surface anomalies between INT_O3 and CLIM_O3 show the direct impact of ozone feedbacks, we conclude that stratospheric ozone actively forces NH surface climate in the aftermath of springtime ozone depletion. Most importantly, only model simulations with interactive ozone can reproduce certain details of the observed surface patterns, especially with regard to anomalies over Europe (Figs. 1 and S5, red boxes). Model experiments with SOCOL_MPIOM corroborate these results (Figs. S1, S2 and S5), albeit with a slightly less pronounced temperature and AO response. In SOCOL-MPIOM, surface signals from ozone minima are enhanced by ozone feedbacks and the differences between CLIM_O3 and INT_O3 are detectable, which lends confidence in the results obtained with WACCM.

\section{Ozone feedback mechanism}

Comparison of stratospheric conditions in the CLIM_O3 and INT_O3 experiments during and after ozone depletion provides insights into the mechanism through which ozone affects surface climate. Ozone depletion is closely tied to stratospheric background conditions with a strong stratospheric vortex and a cold lower stratosphere ${ }^{34}$. A cold, strong polar vortex in the lower stratosphere is generally accompanied by positive temperature anomalies in the upper stratosphere ${ }^{35,36}$ due to increased wave guiding towards and increased dissipation within the upper stratosphere. These upper stratosphere temperature anomalies propagate down to the lower stratosphere once sunlight returns to the polar cap in spring and the vortex starts to dissipate; this is reproduced by both model experiments (Fig. $3 \mathrm{a}$, c). In the lower stratosphere, a stronger polar vortex is associated with reduced transport of ozone-rich air into the polar regions ${ }^{32}$, which contributes to the reduced Arctic ozone abundance. This dynamical contribution can also be seen in the gradual evolution of the ozone minima starting in early winter, when chemical ozone depletion is still negligible (see Fig. S7).

Ozone depletion by anthropogenic halogens initiated by these background conditions exerts an additional forcing on stratospheric temperature and dynamics: due to the loss of ozone caused by chemical depletion, there is less solar absorption in the stratosphere between 50-100 hPa, as seen in Fig. $4 \mathrm{c}$. This leads to larger and more persistent cold anomalies in the lower stratosphere in model simulations that include ozone feedbacks, as highlighted in Fig. $4 \mathrm{a}$. As a result, the depletion event prolongs the lifetime of the polar vortex. In model experiments that include feedbacks between ozone and the circulation, the final warming, which marks the transition from winter to summer, is significantly delayed by up to 10 days compared to experiments with specified ozone (see Table S1). Arctic ozone anomalies therefore actively extend stratospheric winter conditions via their influence on radiative and dynamical feedbacks. Those conditions in the stratosphere lead to a stronger stratosphere-troposphere coupling in the aftermath of ozone depletion events, expressed by a more positive and more persistent positive Northern Annular Mode (NAM) index in the lower stratosphere and troposphere in INT_O3 compared to CLIM_O3 (Fig. 3 b, d). Again, simulations with SOCOL_MPIOM confirm these findings (Figs. S3 and S4).

Additionally, positive temperature anomalies in the upper and middle stratosphere are stronger in simulations including ozone feedbacks (Fig. 4 a, days 30-60). This is due to an increase in planetary wave dissipation following the strengthening of the polar vortex through ozone feedbacks, similar to what has been reported previously for spring conditions with an already weakened polar vortex ${ }^{31,37,38}$. An increase in planetary wave breaking in the upper stratosphere leads to a strengthening of the Brewer-Dobson circulation (BDC), which implies increased downwelling over the pole, resulting in adiabatic heating ${ }^{37}$ (Fig. 4 d, days 30-60).

The ozone feedback mechanism presented here is the first description of the downward impact of springtime ozone depletion in the NH in a mechanistic way and is consistent with our understanding of the dynamical impacts of the ozone hole in the SH: In the Antarctic, stratospheric cooling caused by ozone depletion in spring is usually followed by a strengthening of the polar vortex, which in turn facilitates planetary wave propagation, strengthens the BDC and results in a dynamical heating over the pole ${ }^{38,39}$ and references therein). Even though ozone depletion is much less frequent in the Arctic than in the Antarctic, we conclude that the large contribution of ozone depletion to springtime surface climate as well as the mechanism by which ozone affects the stratospheric circulation is analogous on both hemispheres.

\section{Implications for predictability}

Dynamical variability in the stratosphere has previously been shown to provide skill for subseasonal to seasonal prediction for the Northern Hemisphere, both for winter (e.g. ${ }^{40-42}$ ) and for spring ${ }^{43}$. Such stratospheric predictability bears a broad societal relevance, for example in the context of wind electricity generation ${ }^{44}$ and human health ${ }^{45}$. Forecast systems with an enhanced stratospheric resolution have been shown to provide improved skill for tropospheric predictions ${ }^{46}$. Forecast errors for the North Atlantic region can be traced back to the initial state of the polar stratospheric vortex and uncertainties in stratosphere - troposphere coupling in a sub-seasonal prediction system ${ }^{47}$. Moreover, trends in the future evolution of the stratosphere are projected to influence the troposphere in a future climate, although the direction and magnitude of these trends are uncertain ${ }^{48}$. One potential reason for such errors and uncertainties is that most state-of-the-art prediction systems lack interactive stratospheric ozone chemistry ${ }^{49}$. Indeed, stratospheric ozone information could further enhance sub-seasonal to seasonal predictions, and experiments with a simplified ozone scheme that mimics interactions between dynamics and chemistry 
show promising results ${ }^{22}$.

The results presented here contribute to this discussion in two ways: First, they shed new light on the nature of the ozone-surface climate connection in the $\mathrm{NH}$ - a relationship previously discussed controversially. Our modelling experiments show in a robust manner that springtime NH surface patterns in the aftermath of strong stratospheric ozone depletion cannot be explained by dynamical variability alone. Rather, ozone feedbacks represent an important contribution to the surface response. We therefore conclude that interactive ozone chemistry is essential for weather and climate models to realistically reproduce Northern Hemispheric spring conditions. A second contribution is that these novel findings create new incentives to explore the value of stratospheric ozone for subseasonal to seasonal prediction, and they should serve as a motivation to explore ways to include a more realistic representation of stratospheric ozone in forecast models and to further investigate the prediction skill arising from stratospheric ozone depletion in current and future climate for both hemispheres. Despite the projected Arctic ozone recovery, large dynamical variability will ensue in the future, leading to large episodic springtime depletion ${ }^{50}$. Hence, Arctic ozone will continue playing an important role in future climate variability. 


\section{References}

1. Solomon, S. Stratospheric ozone depletion: A review of concepts and history. Rev. Geophys. 37, 275-316, DOI: https://doi.org/10.1029/1999RG900008 (1999).

2. Henriksen, T., Dahlback, A., Larsen, S. H. \& Moan, J. Ultraviolet-radiation and skin cancer. effect of an ozone layer depletion. Photochem. Photobiol. 51, 579-582, DOI: https://doi.org/10.1111/j.1751-1097.1990.tb01968.x (1990).

3. Ballaré, C. L. et al. Impacts of solar ultraviolet-B radiation on terrestrial ecosystems of Tierra del Fuego (southern Argentina): An overview of recent progress. J. Photochem. Photobiol. B: Biol. 62, 67-77, DOI: https://doi.org/10.1016/ S1011-1344(01)00152-X (2001).

4. Gillett, N. P. \& Thompson, D. W. J. Simulation of Recent Southern Hemisphere Climate Change. Science 302, 273-275, DOI: $10.1126 /$ science. 1087440 (2003).

5. Thompson, D. W. J. \& Solomon, S. Interpretation of Recent Southern Hemisphere Climate Change. Science 296, 895-899, DOI: $10.1126 /$ science.1069270 (2002).

6. Ummenhofer, C. C., Gupta, A. S. \& England, M. H. Causes of Late Twentieth-Century Trends in New Zealand Precipitation. J. Clim. 22, 3 - 19, DOI: 10.1175/2008JCLI2323.1 (2009).

7. Bandoro, J., Solomon, S., Donohoe, A., Thompson, D. W. J. \& Santer, B. D. Influences of the Antarctic Ozone Hole on Southern Hemispheric Summer Climate Change. J. Clim. 27, 6245 - 6264, DOI: 10.1175/JCLI-D-13-00698.1 (2014).

8. Thompson, D. et al. Signatures of the Antarctic ozone hole in Southern Hemisphere surface climate change. Nat. Geosci. 4, 741-749, DOI: 10.1038/ngeo1296 (2011).

9. Gillett, Z. E. et al. Evaluating the Relationship between Interannual Variations in the Antarctic Ozone Hole and Southern Hemisphere Surface Climate in Chemistry-Climate Models. J. Clim. 32, 3131 - 3151, DOI: 10.1175/JCLI-D-18-0273.1 (2019).

10. Son, S.-W., Purich, A., Hendon, H. H., Kim, B.-M. \& Polvani, L. M. Improved seasonal forecast using ozone hole variability? Geophys. Res. Lett. 40, 6231-6235, DOI: https://doi.org/10.1002/2013GL057731 (2013).

11. Lawrence, Z. D. et al. The Remarkably Strong Arctic Stratospheric Polar Vortex of Winter 2020: Links to Record-Breaking Arctic Oscillation and Ozone Loss. J. Geophys. Res. Atmospheres 125, e2020JD033271, DOI: https://doi.org/10.1029/ 2020JD033271 (2020).

12. Manney, G. L. et al. Record-Low Arctic Stratospheric Ozone in 2020: MLS Observations of Chemical Processes and Comparisons With Previous Extreme Winters. Geophys. Res. Lett. 47, e2020GL089063, DOI: https://doi.org/10.1029/ 2020GL089063 (2020).

13. Ivy, D. J., Solomon, S., Calvo, N. \& Thompson, D. W. J. Observed connections of Arctic stratospheric ozone extremes to Northern Hemisphere surface climate. Environ. Res. Lett. 12, 024004, DOI: 10.1088/1748-9326/aa57a4 (2017).

14. Calvo, N., Polvani, L. M. \& Solomon, S. On the surface impact of Arctic stratospheric ozone extremes. Environ. Res. Lett. 10, 094003, DOI: 10.1088/1748-9326/10/9/094003 (2015).

15. Stone, K. A., Solomon, S., Kinnison, D. E., Baggett, C. F. \& Barnes, E. A. Prediction of Northern Hemisphere Regional Surface Temperatures Using Stratospheric Ozone Information. J. Geophys. Res. Atmospheres 124, 5922-5933, DOI: https://doi.org/10.1029/2018JD029626 (2019).

16. Stone, K. A., Solomon, S. \& Kinnison, D. E. Prediction of Northern Hemisphere regional sea ice extent and snow depth using stratospheric ozone information. J. Geophys. Res. Atmospheres 125, e2019JD031770, DOI: https://doi.org/10.1029/ 2019JD031770 (2020).

17. Ayarzagüena, B. \& Serrano, E. Monthly Characterization of the Tropospheric Circulation over the Euro-Atlantic Area in Relation with the Timing of Stratospheric Final Warmings. J. Clim. 22, 6313 - 6324, DOI: 10.1175/2009JCLI2913.1 (2009).

18. Black, R. X. \& McDaniel, B. A. The Dynamics of Northern Hemisphere Stratospheric Final Warming Events. J. Atmospheric Sci. 64, 2932 - 2946, DOI: 10.1175/JAS3981.1 (2007).

19. Domeisen, D. I. V. \& Butler, A. H. Stratospheric drivers of extreme events at the Earth's surface. Commun. Earth \& Environ. 1, 59, DOI: 10.1038/s43247-020-00060-z (2020).

20. Harari, O. et al. Influence of Arctic stratospheric ozone on surface climate in CCMI models. Atmospheric Chem. Phys. 19, 9253-9268, DOI: 10.5194/acp-19-9253-2019 (2019). 
21. Rao, J. \& Garfinkel, C. I. Arctic Ozone Loss in March 2020 and its Seasonal Prediction in CFSv2: A Comparative Study With the 1997 and 2011 Cases. J. Geophys. Res. Atmospheres 125, e2020JD033524, DOI: https://doi.org/10.1029/ 2020JD033524 (2020).

22. Monge-Sanz, B. M. et al. A stratospheric prognostic ozone for seamless Earth System Models: performance, impacts and future. Atmospheric Chem. And Phys. 1-39, DOI: 10.5194/acp-2020-1261 (2021).

23. Gelaro, R. et al. The Modern-Era Retrospective Analysis for Research and Applications, Version 2 (MERRA-2). J. Clim. 30, 5419 - 5454, DOI: 10.1175/JCLI-D-16-0758.1 (2017).

24. Baldwin, M. P. et al. Sudden Stratospheric Warmings. Rev. Geophys. 59, 27.1-37, DOI: https://doi.org/10.1029/ 2020RG000708 (2021).

25. Baldwin, M. P. \& Dunkerton, T. J. Stratospheric Harbingers of Anomalous Weather Regimes. Science 294, 581-584, DOI: 10.1126/science.1063315 (2001).

26. Domeisen, D. I. Estimating the Frequency of Sudden Stratospheric Warming Events From Surface Observations of the North Atlantic Oscillation. J. Geophys. Res. Atmospheres 124, 3180-3194, DOI: https://doi.org/10.1029/2018JD030077 (2019).

27. Afargan-Gerstman, H. \& Domeisen, D. I. V. Pacific Modulation of the North Atlantic Storm Track Response to Sudden Stratospheric Warming Events. Geophys. Res. Lett. 47, 18-10, DOI: https://doi.org/10.1029/2019GL085007 (2020).

28. Marsh, D. R. et al. Climate Change from 1850 to 2005 Simulated in CESM1(WACCM). J. Clim. 26, 7372 - 7391, DOI: 10.1175/JCLI-D-12-00558.1 (2013).

29. Muthers, S. et al. The coupled atmosphere-chemistry-ocean model SOCOL-MPIOM. Geosci. Model. Dev. 7, 2157-2179, DOI: 10.5194/gmd-7-2157-2014 (2014).

30. Smith, K. L., Neely, R. R., Marsh, D. R. \& Polvani, L. M. The Specified Chemistry Whole Atmosphere Community Climate Model (SC-WACCM). J. Adv. Model. Earth Syst. 6, 883-901, DOI: https://doi.org/10.1002/2014MS000346 (2014).

31. Haase, S. \& Matthes, K. The importance of interactive chemistry for stratosphere-troposphere coupling. Atmospheric Chem. Phys. 19, 3417-3432, DOI: 10.5194/acp-19-3417-2019 (2019).

32. Oehrlein, J., Chiodo, G. \& Polvani, L. M. The effect of interactive ozone chemistry on weak and strong stratospheric polar vortex events. Atmospheric Chem. Phys. 20, 10531-10544, DOI: 10.5194/acp-20-10531-2020 (2020).

33. Waugh, D. W. et al. Effect of zonal asymmetries in stratospheric ozone on simulated Southern Hemisphere climate trends. Geophys. Res. Lett. 36, DOI: https://doi.org/10.1029/2009GL040419 (2009).

34. Solomon, S., Garcia, R., Rowland, F. \& Wuebbles, D. On the Depletion of Antarctic Ozone. Nature 321, 755-758, DOI: 10.1038/321755a0 (1986).

35. Kuroda, Y. \& Kodera, K. Variability of the polar night jet in the Northern and Southern Hemispheres. J. Geophys. Res. Atmospheres (1984 - 2012) 106, 20703-20713, DOI: https://doi.org/10.1029/2001JD900226 (2001).

36. Kuroda, Y. \& Kodera, K. Role of the Polar-night Jet Oscillation on the formation of the Arctic Oscillation in the Northern Hemisphere winter. J. Geophys. Res. Atmospheres 109, DOI: https://doi.org/10.1029/2003JD004123 (2004).

37. Charney, J. G. \& Drazin, P. G. Propagation of planetary-scale disturbances from the lower into the upper atmosphere. $J$. Geophys. Res. (1896-1977) 66, 83-109, DOI: https://doi.org/10.1029/JZ066i001p00083 (1961).

38. Lin, P. et al. Dependence of model-simulated response to ozone depletion on stratospheric polar vortex climatology. Geophys. Res. Lett. 44, 6391-6398, DOI: https://doi.org/10.1002/2017GL073862 (2017).

39. Ivy, D. J., Solomon, S. \& Rieder, H. E. Radiative and Dynamical Influences on Polar Stratospheric Temperature Trends. $J$. Clim. 29, 4927 - 4938, DOI: 10.1175/JCLI-D-15-0503.1 (2016).

40. Butler, A. et al. Chapter 11 - Sub-seasonal Predictability and the Stratosphere. In Robertson, A. W. \& Vitart, F. (eds.) Sub-Seasonal to Seasonal Prediction, 223-241, DOI: https://doi.org/10.1016/B978-0-12-811714-9.00011-5 (Elsevier, 2019).

41. Nie, Y. et al. Stratospheric initial conditions provide seasonal predictability of the North Atlantic and Arctic Oscillations. Environ. Res. Lett. 14, 034006, DOI: 10.1088/1748-9326/ab0385 (2019).

42. Domeisen, D. I. V. et al. The Role of the Stratosphere in Subseasonal to Seasonal Prediction: 2. Predictability Arising From Stratosphere-Troposphere Coupling. J. Geophys. Res. 125, 1-20, DOI: https://doi.org/10.1029/2019JD030923 (2020). 
43. Butler, A. H., Perez, A. C., Domeisen, D. I. V., Simpson, I. R. \& Sjoberg, J. Predictability of Northern Hemisphere Final Stratospheric Warmings and Their Surface Impacts. Geophys. Res. Lett. 43, 23, DOI: https://doi.org/10.1029/ 2019GL083346 (2019).

44. Beerli, R., Wernli, H. \& Grams, C. M. Does the lower stratosphere provide predictability for month-ahead wind electricity generation in Europe? Q. J. Royal Meteorol. Soc. 143, 3025-3036, DOI: https://doi.org/10.1002/qj.3158 (2017).

45. Charlton-Perez, A. J., Aldridge, R. W., Grams, C. M. \& Lee, R. Winter pressures on the UK health system dominated by the Greenland Blocking weather regime. Weather. Clim. Extrem. 25, 100218, DOI: https://doi.org/10.1016/j.wace.2019.100218 (2019).

46. Butler, A. H. et al. The Climate-system Historical Forecast Project: do stratosphere-resolving models make better seasonal climate predictions in boreal winter? Q. J. Royal Meteorol. Soc. 142, 1413-1427, DOI: https://doi.org/10.1002/qj.2743 (2016).

47. Kolstad, E. W., Wulff, C. O., Domeisen, D. I. V. \& Woollings, T. Tracing North Atlantic Oscillation Forecast Errors to Stratospheric Origins. J. Clim. 33, 9145 - 9157, DOI: 10.1175/JCLI-D-20-0270.1 (2020).

48. Simpson, I. R., Hitchcock, P., Seager, R., Wu, Y. \& Callaghan, P. The Downward Influence of Uncertainty in the Northern Hemisphere Stratospheric Polar Vortex Response to Climate Change. J. Clim. 31, 6371-6391, DOI: https: //doi.org/10.1175/JCLI-D-18-0041.1 (2018).

49. Domeisen, D. I. et al. The Role of the Stratosphere in Subseasonal to Seasonal Prediction: 1. Predictability of the Stratosphere. J. Geophys. Res. Atmospheres 125, e2019JD030920, DOI: https://doi.org/10.1029/2019JD030920 (2020).

50. Bednarz, E. M. et al. Future Arctic ozone recovery: the importance of chemistry and dynamics. Atmospheric Chem. Phys. 16, 12159-12176, DOI: 10.5194/acp-16-12159-2016 (2016). 


\section{Methods \\ Models}

We investigate ozone feedbacks in two chemistry climate models, WACCM version 4 and SOCOL-MPIOM. WACCM (Whole Atmosphere Community Climate Model) is the atmospheric component of the NCAR Community Earth System Model version 1 (CESM1). It is a fully interactive high-top chemistry climate mode ${ }^{28}$ coupled to an active ocean ${ }^{51}$ and sea ice components ${ }^{52}$. Extending to the lower thermosphere $\left(5.1 \cdot 10^{-6} \mathrm{hPa}\right)$ in altitude with 66 vertical levels and a well resolved stratosphere ${ }^{28}$, WACCM has been documented to capture stratospheric trends and variability reasonably well and has been used in many recent studies analysing interannual stratospheric variability (e.g..$^{9,31,32}{ }^{53}$ ). WACCM has a horizontal resolution of $1.9^{\circ}$ latitude and $2.5^{\circ}$ longitude ${ }^{28}$, while the ocean has a nominal latitude-longitude resolution of $1^{\circ}$. Being coupled to an interactive chemistry scheme ${ }^{54}$, WACCM calculates ozone concentrations over a set of chemical equations between a total of 59 species 28 and therefore actively simulates feedbacks between ozone and dynamics. In addition, WACCM can be run in a "specified chemistry" mode, where ozone concentrations and other radiative species are prescribed in the form of zonal mean, monthly mean climatologies ${ }^{30}$.

SOCOL (SOlar Climate Ozone Links) version 3 is a chemistry climate model based on the general circulation model MA-ECHAM5 and the chemistry transport model MEZON (Model for Evaluation of oZONe trends, ${ }^{55}$ ), which are interactively coupled via 3-D temperature and wind fields and through radiative forcing induced by several greenhouse gases (water vapor, ozone, methane, nitrous oxide, and chlorofluorocarbons (CFCs) $)^{56}$. MEZON includes a set of 140 gas-phase, 46 photolysis and 16 heterogeneous reactions between 41 species. SOCOL in its default configuration therefore incorporates feedbacks between ozone and dynamics. Like WACCM, SOCOL can be run in a "specified chemistry" mode through decoupling of chemistry and general circulation model, in which case ozone concentrations are prescribed as zonal mean, monthly mean climatologies ${ }^{29}$. The model version SOCOL-MPIOM used in this study is additionally coupled to the ocean-sea-ice model MPIOM $^{29}$. SOCOL-MPIOM has a model top of $0.01 \mathrm{hPa}$ with a well resolved stratosphere and 39 vertical levels and a horizontal resolution of $\mathrm{T} 31\left(3.75^{\circ} \times 3.75^{\circ}\right)^{56}$. Although showing a cold pole bias in the stratosphere during winter ${ }^{56}$, SOCOL has been documented to capture the annual ozone cycle and ozone trends ${ }^{56}$ as well as stratospheric variability ${ }^{29}$ reasonably well.

\section{Boundary Conditions}

Since both WACCM and SOCOL-MPIOM are models with fully coupled radiation, chemistry and dynamics, both models incorporate ozone-circulation feedbacks. For the study at hand, we run both models under invariant year-2000 boundary conditions with fixed, seasonally varying atmospheric greenhouse gas (GHG) concentrations including ozone depleting substances (ODSs) and a nudged quasi-biennial oscillation (QBO). For SOCOL, GHG concentrations and ozone depleting substances (ODS) have been prescribed following the approach in ${ }^{56}$ and the QBO has been nudged according to ${ }^{57}$. In WACCM, a perpetual 28-month QBO cycle was forced based on the setup described in ${ }^{28}$. Boundary conditions were prescribed following the CMIP5 forcing data sets ${ }^{58}$. With concentrations of ODSs being set to year-2000 levels, this setup yields a high polar stratospheric ozone variability in spring and thus maximised ozone feedbacks. It also removes the effects of climate change, thereby aiding the statistical analysis.

\section{Experiment design}

To assess the impact of ozone feedbacks, we contrast runs with fully interactive and specified ozone chemistry in both models. Within the fully interactive ozone runs (INT_O3), the free running models interactively calculate ozone concentrations, therefore allowing the simulation of ozone feedbacks into the general circulation. Averaging over all 200 simulated years of INT_O3 SOCOL and INT_O3 WACCM, monthly mean ozone climatologies are derived and used as prescribed forcings in simulations without interactive ozone. For runs with specified ozone chemistry (CLIM_O3) we use a hybrid model setup: while interactive ozone is still being calculated and saved as output, it is decoupled from the models' radiation schemes and replaced by the monthly mean, zonal mean ozone climatology from INT_O3. In this setup without interannually varying radiative ozone forcing, ozone feedbacks are not simulated; ozone thus acts as a passive tracer of dynamical variability in the stratosphere. Comparisons with runs with interactive ozone chemistry therefore allow us to draw conclusions about the role of ozone feedbacks in the climate system. To account for the high interannual stratospheric variability within the system, we simulate a total of 200 model years for each of the four runs.

\section{Sampling of ozone minima}

Springtime ozone minima are defined based on daily zonally averaged ozone mixing ratios. To exclude outliers from being counted as "ozone minimum", a 5-day running mean of ozone mixing ratios is derived from the daily data. In order to detect 


$$
S=\frac{H \cdot N^{2}}{R^{*}}
$$

$$
\frac{\delta \bar{T}}{\delta t}=S \cdot \bar{w}^{*}
$$

where $\chi_{O_{3}}(p)$ denotes the ozone mixing ratio at pressure level $p, \Delta p$ describes the distance to the next pressure level in Pa, $g$ is the gravitational constant (in $\frac{\mathrm{cm}}{\mathrm{s}^{2}}$ and $m_{\text {air,d }}$ the mass of dry air (in $\frac{\mathrm{g}}{\text { molec }}$ ). For each year within a dataset, the minimum polar cap mean $\left(60-90^{\circ} \mathrm{N}\right)$ partial ozone column value within March and April is selected. For each dataset, the $25 \%$ of years with the lowest minimum partial ozone column in March and April are considered "low ozone years" (10 events in MERRA2, 50 events for each model simulation). The day at which the minimum ozone value occurs is considered the "central ozone minimum date". If not stated otherwise, the data is weighted with the cosine of latitude for latitudinal averaging.

\section{Calculation of anomalies}

To calculate anomalies of a variable, a climatology for the respective variable is derived for each day of the year by averaging each calendar day over all years available in the dataset. This daily climatology is subtracted from the daily variable values to obtain daily anomalies. For MERRA2, a daily climatology is derived by averaging over the years 1980 to 2019. Since the spring in 2020 exhibited particular strong anomalies in both stratospheric and surface climate and the MERRA2 record is comparably short, the year 2020 is excluded in the calculation of the daily climatology ${ }^{11}$.

\section{Bootstrapping significance test}

A 1-sample bootstrapping significance test is performed to estimate the significance of mean anomalies composited around the ozone minimum (e.g. ${ }^{31,32}$ ). For a composite including the $25 \%$ most extreme springtime ozone minima, 500 random composites are created by sampling data around the respective central ozone minimum dates in random years to create a normal distribution of random composites. The actual composite is considered significantly different from zero if it differs more than 2 standard deviations from the mean of the randomly created distribution, which is equivalent to a significance at the $95.4 \%$ level. The procedure for a 2-sample bootstrapping significance test is conducted accordingly: To compare two composites, random composites are created as described above in both datasets and the difference of both random composites was calculated. Repeating this procedure 500 times, we create a distribution of 500 random samples. The difference between both samples is considered significant if it differs more than 2 standard deviations from the mean value of the random distribution.

\section{Calculation of Arctic Oscillation and NAM indices}

While the AO and NAM in general describe the same phenomenon of simultaneous fluctuations in geopotential height of opposite sign over the polar cap and lower latitudes ${ }^{25}$, we refer to the NAM as the pattern on all vertical levels, whereas the $\mathrm{AO}$ is used to describe the near-surface profile at $1000 \mathrm{hPa}^{25}$. Empirical Orthogonal Functions (EOFs) are used to calculate the AO and NAM indices following method 3 in $^{59}$. For each pressure level, we calculate the leading EOF spatial pattern of year-round daily zonal mean geopotential height anomalies north of $20^{\circ} \mathrm{N}$ while applying latitudinal weights as the square root of the cosine of latitude ${ }^{25}$. Daily geopotential height anomalies are then projected onto the EOF loading pattern to find the Principal Component (PC) time series. PCs are normalized to unit variance to derive the respective AO and NAM indices.

\section{Calculation of dynamical heating rate}

We calculate the vertical $\left(\bar{w}^{*}\right)$ and meridional $\left(\bar{v}^{*}\right)$ component of the residual circulation according to the transformed Eulerian mean framework described by equations 3.5.1 and 3.5.2 in ${ }^{60}$. To examine changes in temperature induced by ozone related changes in the Brewer Dobson Circulation (BDC), we calculate the adiabatic dynamical heating in the Arctic stratosphere based on the Quasi-Geostrophic (QG) theory according to

where $\bar{T}$ is the zonal mean temperature and $S$ the atmospheric stability parameter ${ }^{61}$ which can be calculated according to 
${ }^{62} . N^{2}$ hereby denotes the Brunt-Väisälä frequency, $H$ the atmospheric scale height and $R^{*}$ the specific gas constant for mixed gases.

\section{Calculation of Final Warming date}

Final warmings are defined as the first date when the zonal mean wind at $60^{\circ} \mathrm{N}$ and $10 \mathrm{hPa}$ turns easterly and does not return to westerlies for more than 10 consecutive days until the next winter ${ }^{63}$. Uncertainty in the final warming date is estimated based on the standard deviation.

\section{References}

51. Danabasoglu, G. et al. The CCSM4 Ocean Component. J. Clim. 25, 1361 - 1389, DOI: 10.1175/JCLI-D-11-00091.1 (2012).

52. Holland, M. M., Bailey, D. A., Briegleb, B. P., Light, B. \& Hunke, E. Improved Sea Ice Shortwave Radiation Physics in CCSM4: The Impact of Melt Ponds and Aerosols on Arctic Sea Ice. J. Clim. 25, 1413 - 1430, DOI: 10.1175/ JCLI-D-11-00078.1 (2012).

53. Rieder, H. E., Chiodo, G., Fritzer, J., Wienerroither, C. \& Polvani, L. M. Is interactive ozone chemistry important to represent polar cap stratospheric temperature variability in Earth-System Models? Environ. Res. Lett. 14, 044026, DOI: 10.1088/1748-9326/ab07ff (2019).

54. Kinnison, D. E. et al. Sensitivity of chemical tracers to meteorological parameters in the MOZART-3 chemical transport model. J. Geophys. Res. Atmospheres 112, DOI: https://doi.org/10.1029/2006JD007879 (2007).

55. Egorova, T., Rozanov, E., Zubov, V. \& Karol, I. Model for investigating ozone trends (MEZON). Izvestiya - Atmospheric Ocean. Phys. 39, 277-292 (2003).

56. Stenke, A. et al. The SOCOL version 3.0 chemistry-climate model: description, evaluation, and implications from an advanced transport algorithm. Geosci. Model. Dev. 6, 1407-1427, DOI: 10.5194/gmd-6-1407-2013 (2013).

57. Brönnimann, S., Annis, J. L., Vogler, C. \& Jones, P. D. Reconstructing the quasi-biennial oscillation back to the early 1900s. Geophys. Res. Lett. 34, DOI: https://doi.org/10.1029/2007GL031354 (2007).

58. Meinshausen, M. et al. The RCP greenhouse gas concentrations and their extensions from 1765 to 2300 . Clim. Chang. 109, 213-241, DOI: https://doi.org/10.1007/s10584-011-0156-z (2011).

59. Baldwin, M. P. \& Thompson, D. W. A critical comparison of stratosphere-troposphere coupling indices. Q. J. Royal Meteorol. Soc. 135, 1661-1672, DOI: https://doi.org/10.1002/qj.479 (2009).

60. Andrews, D. G., Holton, J. R. \& Leovy, C. B. Middle atmosphere dynamics (Academic Press, San Diego, California, 1987).

61. Calvo, N., Garcia, R. R. \& Kinnison, D. E. Revisiting Southern Hemisphere polar stratospheric temperature trends in WACCM: The role of dynamical forcing. Geophys. Res. Lett. 44, 3402-3410, DOI: https://doi.org/10.1002/2017GL072792 (2017).

62. Garcia, R. R., Kinnison, D. E. \& Marsh, D. R. "World avoided" simulations with the Whole Atmosphere Community Climate Model. J. Geophys. Res. Atmospheres 117, DOI: https://doi.org/10.1029/2012JD018430 (2012).

63. Butler, A. H. \& Gerber, E. P. Optimizing the Definition of a Sudden Stratospheric Warming. J. Clim. 31, $2337-2344$, DOI: 10.1175/JCLI-D-17-0648.1 (2018). 


\section{Data availability}

The modelling data used in this study will be made available on the ETH Research Collection. The MERRA2 reanalysis data can be downloaded from the Goddard Earth Sciences Data and Information Services Center (GES DIC) (https://disc.gsfc.nasa. gov/datasets?keywords=\%22MERRA-2\%22\&page=1\&source=Models\%2FAnalyses\%20MERRA-2).

\section{Code availability}

All codes and scripts used for the analysis in this study are available from the corresponding author upon reasonable request.

\section{Acknowledgements}

We are grateful for the assistance from U. Beyerle in data management and thank S. Muthers for support in the chemistryclimate modelling with SOCOL-MPIOM. Support from the Swiss National Science Foundation through Ambizione Grant PZ00P2_180043 for M.F. and G.C, and project PP00P2_170523 to D.D. is gratefully acknowledged.

\section{Author contributions}

G.C. conceived the modelling experiments, G.C., M.F., A.S. and J.A. conducted the modelling experiments, G.C. and M.F. processed the data, M.F., G.C., T.P., D.D. and S.F. analysed and interpreted the results. M.F. wrote the paper with input from all authors.

\section{Competing interests}

The authors declare no competing interests.

\section{Additional information}

Supplementary information is available for this study. 

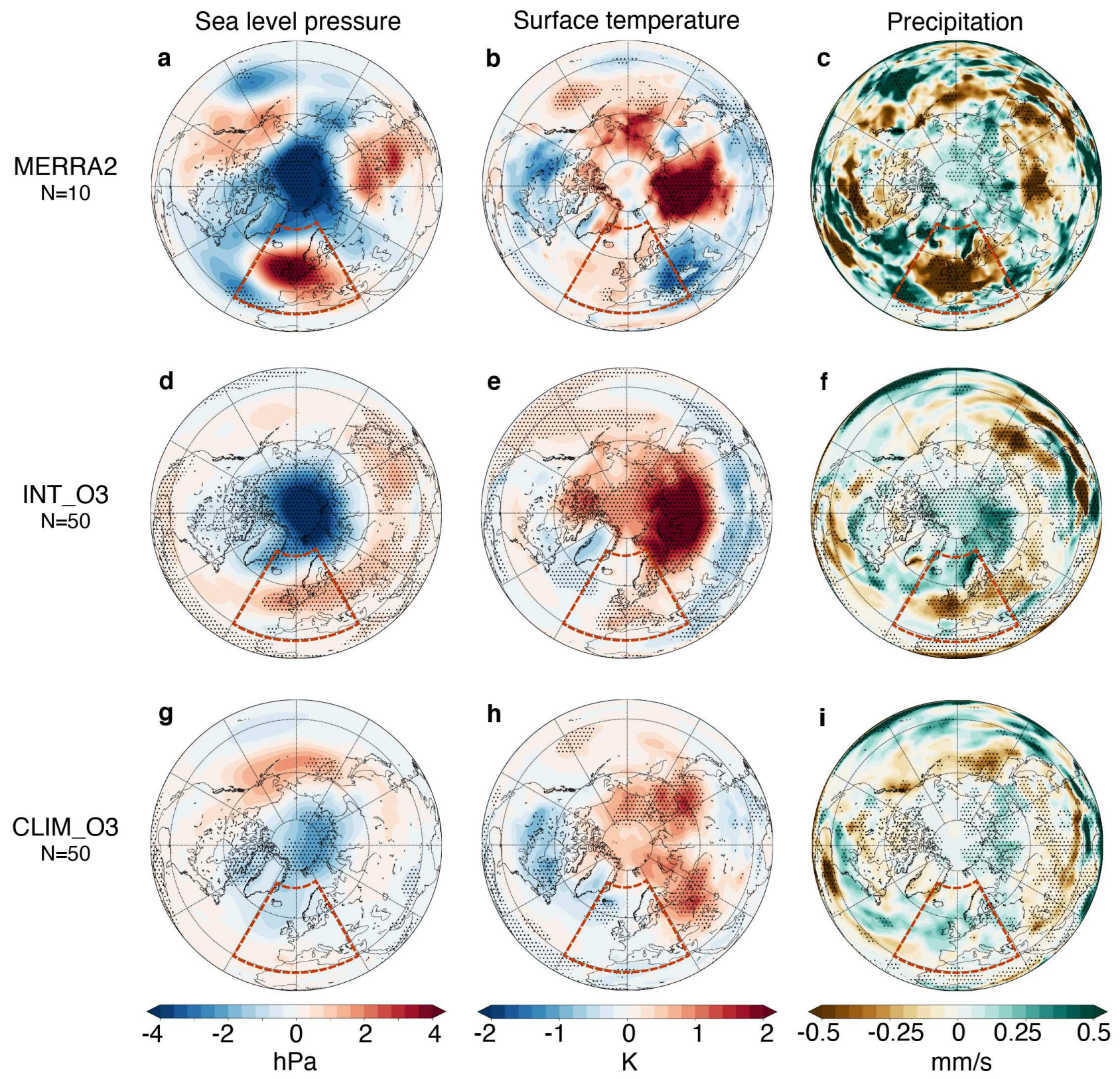

Figure 1. Surface climate following springtime Arctic ozone depletion. Composites of SLP (a, d, g), surface temperature (b, e, h) and precipitation (c, f, i) in observations (top row), WACCM INT_O3 (middle row) and CLIM_O3 (bottom row) after ozone minima in the 25\% most extreme winters (average over the 30 days after the largest ozone minimum). Stippling shows significance on a $4.6 \%$ level following a bootstrapping test. By definition, surface patterns shown are within March-May. Red boxes highlight the region over Europe, where differences between INT_O3 and CLIM_O3 are particularly remarkable. The following springs are included in the observations (top row): 2020, 2011, 2005, 2002, 2000, 1997, 1996, 1995, 1993, 1990. 


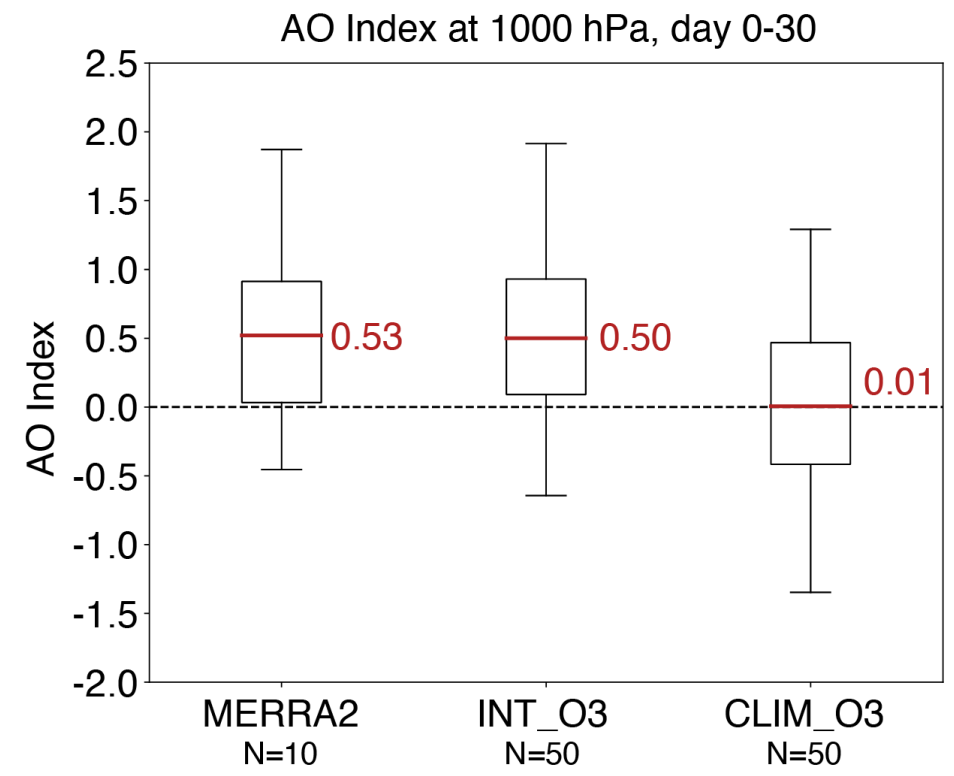

Figure 2. The Arctic Oscillation index following springtime Arctic ozone depletion. Distribution of mean Arctic Oscillation Index $\left(20-90^{\circ} \mathrm{N}\right)$ at $1000 \mathrm{hPa}$ averaged over the 30 days following an ozone minimum for WACCM (INT_O3 and CLIM_O3) and MERRA2. Red lines and numbers indicate the mean Arctic Oscillation index in the month after the ozone minima averaged over the $25 \%$ most extreme winters. The upper and lower edges of the box show the upper and lower quartile, the whiskers represent the maximum and minimum values of the respective distribution. 

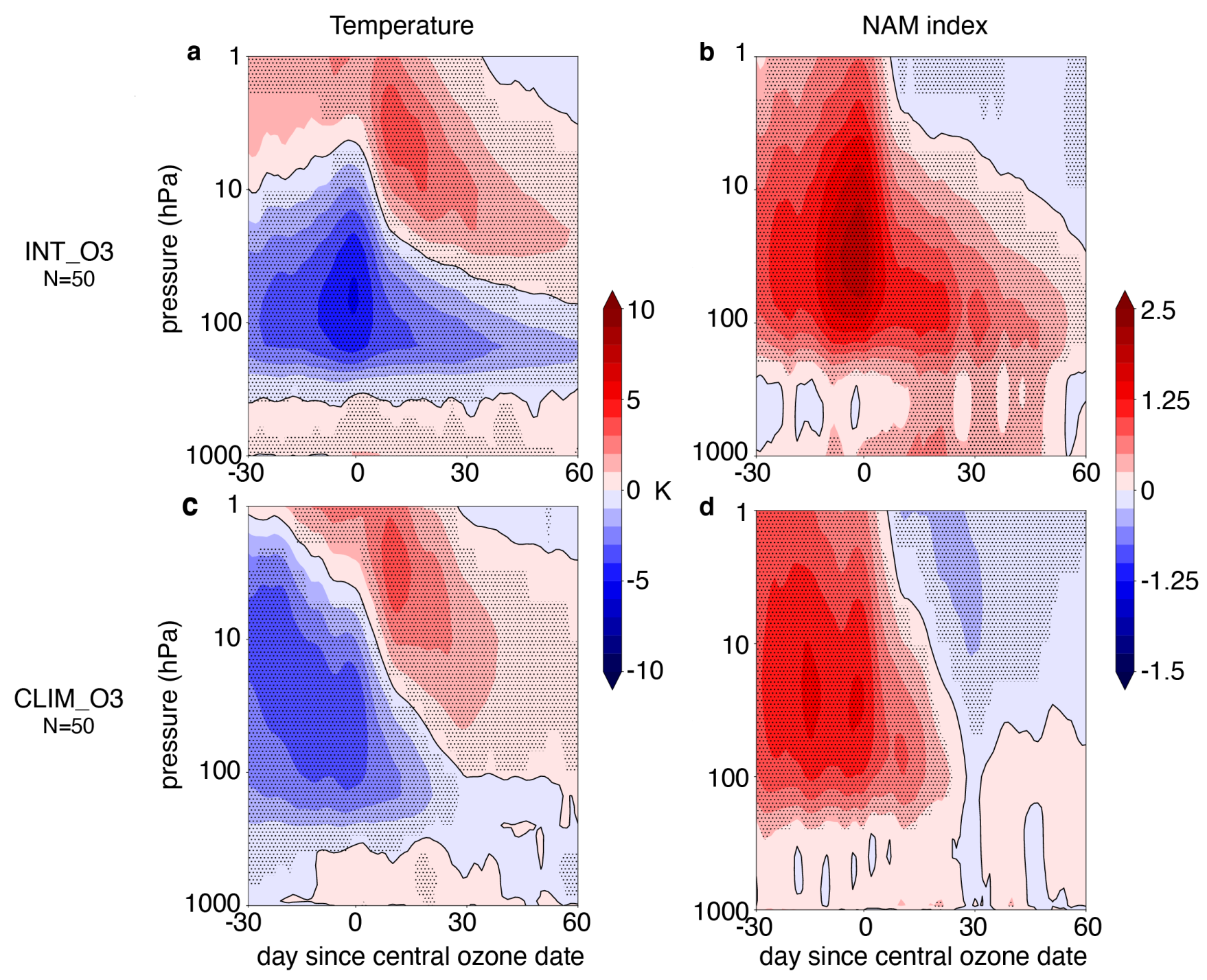

Figure 3. Influence of ozone depletion on stratosphere-troposphere coupling. Composites of polar cap (60 $\left.90^{\circ} \mathrm{N}\right)$ temperature anomalies (a, c) and Northern Annular Mode (NAM) index $\left(20-90^{\circ} \mathrm{N}\right)(\mathrm{b}, \mathrm{d})$ around the ozone minima in WACCM INT_O3 and CLIM_O3. Day zero indicates the date with the largest extent of the ozone minima. Stippling shows significance on a $4.6 \%$ level following a bootstrapping test (see methods). 

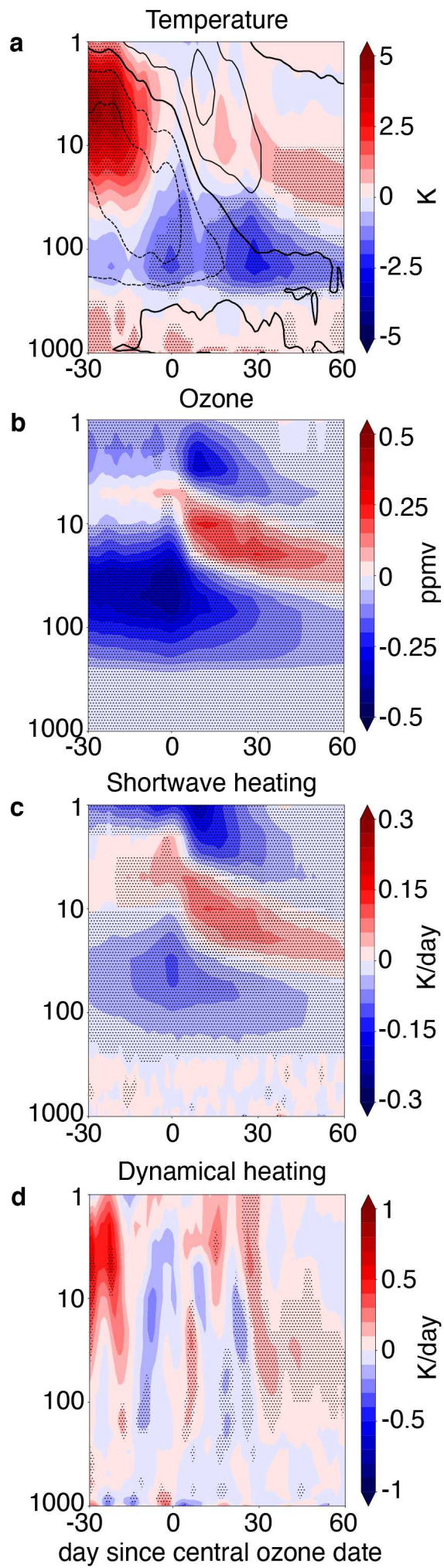

Figure 4. Influences of ozone depletion on temperature through shortwave and dynamical heating.

Differences of polar cap $\left(60-90^{\circ} \mathrm{N}\right)$ temperature (a), ozone (b), shortwave heating (c) and dynamical heating (d) anomalies between INT_O3 and CLIM_O3 around the ozone minima in WACCM. Day zero indicates the date with the largest extent of the ozone minima. Contour lines in the temperature plot show temperature anomalies in CLIM_O3 with a contour interval of $1.5 \mathrm{~K}$. Stippling shows significance on a $4.6 \%$ level following a bootstrapping test. 


\section{Supplementary Files}

This is a list of supplementary files associated with this preprint. Click to download.

- SupplementaryInformationFriedel.pdf 